\title{
O PROTAGONISMO DOS ALUNOS DO ENSINO MÉDIO/TÉCNICO NO DESENVOLVIMENTO DO APLICATIVO "FUEL ASK" ABORDANDO O TEMA COMBUSTÍVEIS
}

Cinthia Diniz de Almeida Jussara Lopes Miranda

"Educação não transforma o mundo. Educação muda pessoas. Pessoas transformam o mundo". (Paulo Freire)

\section{Introdução}

Há alguns anos, a discussão sobre o uso das Tecnologias Digitais de Informação e Comunicação (TDIC), tornou-se um assunto relevante e necessário no cotidiano tanto das instituições escolares, como dos professores/mediadores e alunos, na complementação da educação no século XXI.

Os computadores, smartphones e tablets ganharam espaço em nossa sociedade, podendo ser empregados também no desenvolvimento de ensino e aprendizagem com a incorporação de suas diversas funcionalida- 
des. O uso de dispositivos móveis como smartphones e tablets apresenta relativa "facilidade" de manuseio e acessibilidade para o ensino, especialmente para a faixa etária de crianças e adolescentes e em particular na área de ciências da natureza.

No entanto, apesar do uso disseminado de celulares, especialmente para a geração atual de jovens e adolescentes, muitos professores optam por proibi-los em sala de aula (MATEUS, 2015), o que pode ser compreendido e justificado por um lado - o da concepção das interações sociais de aprendizagem, por exemplo, mas que também pode ser explorado, por outro, o do desafio da associação tecnológica ao protagonismo dos alunos. (CINELLI, 2003)

O uso de TIDICs pode, então, contribuir para a motivação das gerações mais jovens por incentivá-las a desenvolver a autonomia, a oportunidade para a pesquisa e o processo de interação e intercolaboração (MAHI, 2019; HADDAD, 2017). Essas tecnologias podem contribuir para o processo de aprendizagem através do desenvolvimento e emprego de materiais pedagógicos que inspirem e encorajam as habilidades e aptidões dos alunos. (HADDAD, 2017).

É nesta abordagem - o do resgaste e promoção do protagonismo dos alunos - que este capítulo se fundamenta. Deste modo, o uso de dispositivos móveis pode se 
tornar motivador e utilitário, se estiver engajado em atividades didáticas dinamizadas pelos alunos e mediadas pelo docente. No lugar de obstáculos e itens proibidos (mas, usados furtivamente), estes dispositivos móveis podem ser ferramentas para a valorização da criatividade e aprendizagem, inserindo-os no contexto das discussões temáticas disciplinares, trazendo o mundo virtual para os processos de abertura das paredes dos espaços formais de nossas salas de aula.

A aprendizagem não ocorre deste modo, pela repetição, pelo reforço do discurso dos mestres ou pela cópia de suas palavras, mas, ao contrário, através de um processo de construção dos próprios aprendentes que associam as suas experiências sociais, as suas novas formas de expressão e compreensão, utilizando os recursos tecnológicos que dispõem e fazem já parte do seu cotidiano de interação.

Torna-se necessário e premente considerar o aluno no seu meio social, sem negligenciar sua historicidade, nem ignorar os recursos tecnológicos que dispõem, quando assim os dispuserem, envolvendo-os no processo de ensino e aprendizagem. Os aparelhos celulares podem, assim, ser transformados de isoladores a mediadores de interação, de individualizadores a compartilhadores de ideias, de desviadores da discussão temática das aulas a protagonistas para a concretização de projetos em conjunto. 
A era digital, da qual não podemos escapar, entraria na sala de aula, não para sair dela furtivamente por desvios nos seus aplicativos, mas para abrir possibilidades, dando novo espaço à criação de quem aprende, mediatizado pelas reflexões críticas do que e para que se aprende.

A contextualização surge espontaneamente a partir das problematizações feitas pelos alunos acerca da visão de mundo que têm em relação ao conhecimento científico vigente, tecendo junto diferentes áreas do saber na forma natural como elas podem ser compreendidas: juntas e interligadas. Contextualizar estaria intrinsecamente associado à problematização, no seu significado mais positivo, o da inquietação.

\begin{abstract}
“[...] contextualizar seria problematizar, investigar e interpretar situações/fatos significativos para os alunos de forma que os conhecimentos químicos auxiliassem na compreensão e resolução dos problemas [...]" (SILVA, 2003, p. 26).
\end{abstract}

Em um processo contextualizado de aprendizagem, o aluno participa dinamicamente da ação educativa através da interação com os métodos e meios que dispõem para organizar a própria experiência.

Assim, a relação entre o educador e educando deve adquirir o processo de incentivo a curiosidade e criati- 
vidade, em vez de matá-las por meio de cópias e repetições, pois é através da valorização e significação do conhecimento construído a partir do próprio educando que a aprendizagem pode ocorrer.

"Antes de qualquer tentativa de discussão de técnicas, de materiais, de métodos para uma aula dinâmica assim, e preciso, indispensável mesmo, que o professor se ache "repousado" no saber de que a pedra fundamental e a curiosidade do ser humano. E ela que me faz perguntar, conhecer, atuar, mais perguntar, reconhecer". (FREIRE, 1996, p. 86)

O que podemos entender que o educador ou educadora não pode ser um facilitador no ensino, o que traduz a exigência da formação docente para o exercício pleno de sua função pedagógica, enquanto articulador do processo ensino e aprendizagem.

Portanto, o educador é desafiado a manter o educando sempre em busca de uma formação permanente, dinâmica e evolutiva, buscando na teoria e na prática, trazendo o saber para a realidade do educando e provocando inquietações que o estimulam a progredir ainda mais, atribuindo ao programa curricular, uma interdisciplinaridade nos conteúdos, um novo "olhar" do conhecimento não-dissociado de quem o vivencia. 
Para Paulo Freire, educar exige comprometimento com a aprendizagem, em busca de uma ação inovadora do pensamento crítico, na aceitação do novo e da assunção da identidade cultural, é o ensinar de forma humanizadora e não somente na transmissão de conhecimento, criando uma esperança para possíveis mudanças sociais, fundamentado em "uma educação que liberte, que não adapte, domestique ou subjugue" (FREIRE, 2006, p. 45).

A interdisciplinaridade, o diálogo entre os saberes, deve fluir naturalmente, indo no sentido contrário da excessiva fragmentação disciplinar que acaba por induzir e efetivar, inclusive, a compartimentalização do pensamento, que pode ser designado como o pensar no quadrado, limitado e por isso, muito distanciado da realidade, da problematização, da contextualização. A transdisciplinaridade pode ir além deste diálogo, promovendo uma visão e abordagem mais ampla, para além do disciplinar, com o enfoque no que é mais precioso - o próprio tema em si, a questão, o problema. Mas, ao mesmo tempo em que a transdisciplinaridade é mais encantadora justamente por ser mais próxima da realidade, também é mais desafiadora, já que pode esbarrar nas defesas humanas desejosas de um saber dominado e dominador. Com a Carta da Transdisciplinaridade - CETRANS, que, em seu Art. $3^{\circ}$, define que:

Artigo 3: A Transdisciplinaridade é complementar à abordagem disciplinar; ela faz 
emergir novos dados a partir da confrontação das disciplinas que os articulam entre si; ela nos oferece uma nova visão da Natureza e da Realidade. A transdisciplinaridade não procura o domínio de várias disciplinas, mas a abertura de todas as disciplinas ao que as une e as ultrapassa.

O papel do professor como facilitador deste processo ensino e aprendizagem-realidade é fundamental para permitir que os alunos reconheçam e desenvolvam suas habilidades, tornando-os capazes de acreditar em si mesmos e na atribuição de novos significados construídos a partir das suas articulações com o mundo.

O referencial do professor facilitador e mediador que selecionamos para dialogar com Paulo Freire foi o psicólogo Vygotsky que propôs a aprendizagem como sendo realizada através da mediação e integração, fortemente influenciada pelas experiências concretas vivenciadas (VYGOTSKY, 1991, 1998).

É no brinquedo que a criança aprende a agir numa esfera cognitiva, ao invés de uma esfera visual externa, dependendo das motivações e tendências internas, e não dos incentivos fornecidos pelos objetos. (VYGOTSKI, 1991, p. 109-110).

É nesse contexto construtivista e transdisciplinar, ou pelo menos, interdisciplinar, que se propõe o desenvolvimento de um aplicativo didático a ser disponível em 
celular ou computador, como ferramenta pedagógica motivadora para o processo de ensino e aprendizagem, com a abordagem temática em combustíveis fósseis e biocombustíveis, integrando o conhecimento químico ao de informática, ou melhor, o de informática ao químico, com proposições reflexivas a serem discutida à luz de uma educação ambiental crítica.

No que diz respeito à Educação Ambiental, Loureiro afirma que:

Educação ambiental é uma perspectiva que se inscreve e se dinamiza na própria educação, formada nas relações estabelecidas entre as múltiplas tendências pedagógicas e do ambientalismo, que têm no "ambiente" e na "natureza" categorias centrais e identitárias. Neste posicionamento, a adjetivação "ambiental" se justifica tão somente à medida que serve para destacar dimensões "esquecidas" historicamente pelo fazer educativo, no que se refere ao entendimento da vida e da natureza, e para revelar ou denunciar as dicotomias da modernidade capitalista e do paradigma analítico-linear, não dialético, que separa: atividade econômica, ou outra, da totalidade social; sociedade e natureza; mente e corpo; matéria e espírito, razão e emoção etc. (LOUREIRO, 2004; p.82).

Assim, de acordo com os conceitos de Loureiro (2004), observa-se o trazer da espécie humana para a sua historicidade, pertencimento planetário, reconhecimento 
como ser social dentro de sua própria espécie e com as outras também, ciente da sua finitude e da sua ação transformadora e que sofre transformação.

Relatamos, neste capítulo, o trabalho realizado no âmbito da dissertação de mestrado em ensino de química que teve como objetivo promover o protagonismo dos alunos do ensino médio profissionalizante de informática no processo de ensino e aprendizagem e interação cooperativa, desenvolvendo um aplicativo educacional que pode ser utilizado tanto em celulares, como em computadores, abordando o tema "Combustíveis".

Este trabalho foi desenvolvido na instituição de ensino Escola Técnica Estadual Santa Cruz - ETESC / FAETEC, em conjunto aos alunos do Curso de Ensino médio/Técnico em Informática, Rio de Janeiro e no espaço "Nave do Conhecimento", em Santa Cruz, que é um projeto desenvolvido pela Prefeitura do RJ.

\section{Desenvolvimento}

Este trabalho teve como objetivo promover o protagonismo dos alunos do ensino médio/técnico de informática no desenvolvimento de um aplicativo educacional sobre biocombustíveis, para ser utilizado tanto em celula-

${ }^{1}$ https://navedoconhecimento.rio/ 
res, como computadores. Ele foi realizado em colaboração com a Escola Técnica Estadual Santa Cruz ETESC/FAETEC.

O trabalho foi iniciado e realizado em sala de aula, tanto nas aulas de química, como na utilização das salas de aula de informática e no espaço "Nave do Conhecimento", todos situados no Bairro de Santa Cruz/RJ; sendo um espaço não formal que foi utilizado pelos alunos e pela professora para realização do projeto. $\mathrm{O}$ seu desenvolvimento foi realizado com os alunos do primeiro ano do ensino médio/técnico em informática, no ano letivo de 2017.

Além disso, o trabalho pôde contextualizar o ensino do tema “combustíveis" e a Química Ambiental (EA) no âmbito do conhecimento químico, com o enfoque em Biodiesel; e ainda promover a interdisciplinaridade entre outras disciplinas, como a informática e a química; além da química ambiental, impactos ambientais, combustíveis e a Educação Ambiental;

A mediação para a aprendizagem coletiva e interativa entre os alunos destacou-se como outro objetivo no desenvolvimento deste trabalho, tornando o aluno o protagonista de seu próprio aprendizado, utilizando de espaços formais e não formais para a construção de seu conhecimento. 
O desenvolvimento deste aplicativo teve como público específico, os alunos de ensino profissionalizante do ensino médio/técnico do curso de informática. Porém, o desenvolvimento do aplicativo, foi organizado para atender o público em geral e profissionais da área de educação.

A metodologia empregada, neste trabalho, foi a de pesquisa ação, na qual a docente pesquisadora atuou como mediadora no processo de aprendizagem. Também foram empregados questionários híbridos propositivos para o acompanhamento e avaliação das atividades realizadas que não serão apresentadas neste capítulo, mas estão disponibilizadas na dissertação ${ }^{2}$ de mestrado desenvolvida.

Este trabalho foi desenvolvido em quatro fases principais:

1) Dinâmica de interdisciplinaridade entre a química e a informática-proposição de jogos;

2) Proposição do tema gerador biocombustíveis;

2 ALMEIDA, C. D. 2019. "FUEL ASK": O Desenvolvimento de um Aplicativo na Contextualização do Tema Combustíveis no Ensino de Química. Tese (Mestrado em Ensino de Química - Modalidade Profissional) - Instituto de Química, Universidade Federal do Rio de Janeiro. Rio de Janeiro, p.135. 2019 
3) Desenvolvimento do aplicativo feito pelos alunos com o tema gerador;

4) A contextualização temática do tema combustível em sala de aula na instituição de ensino-FAETEC, Rio de Janeiro sobre "O que são combustíveis? Para que servem? A qualidade dos combustíveis nos afeta?", "O que é biodiesel?" "Utilizando conteúdos sobre o biodiesel no Brasil" e a utilização do espaço Nave do Conhecimento, para o desenvolvimento do aplicativo móvel "FUEL ASK".

Estas fases serão detalhadas, a seguir, nas duas diferentes e sequenciais etapas de realização.

Fase I - Dinâmica de interdisciplinaridade entre a química e a informática-proposição de jogos

1) Contextualização na interdisciplinaridade entre a química e a informática - A atividade foi proposta primeiramente em grupos, onde os alunos teriam que desenvolver jogos em química, abordando o conteúdo da disciplina do $1^{\circ}$ bimestre (Tabela periódica, Ligações químicas e Funções inorgânicas);

2) A partir do aplicativo desenvolvido foram trabalhados novos conceitos da disciplina, para podermos aprimorar o aplicativo abordando o conteúdo sobre combustíveis e a química; foram realizadas aulas teóricas com os alunos 
abordando a contextualização temática sobre combustíveis, biocombustíveis e biodiesel;

3) Proposição do desenvolvimento do aplicativo aos alunos;

4) Divisão dos alunos em grupos, com atividades diferenciadas;

5) Início das atividades para o desenvolvimento do aplicativo;

6) Seleção dos itens relativos ao tema gerador a serem utilizados no aplicativo (feita pelos alunos, com a mediação do docente);

7) Avaliação dos primeiros testes do aplicativo, feito entre os alunos;

8) Apresentação do uso do aplicativo para a turma e para a docente.

9) Avaliação do uso do aplicativo a partir da apresentação do mesmo para outra turma do ensino médio/técnico de informática (segundo ano) mediado pela docente, com o uso de um questionário, para análise sobre a aplicabilidade, viabilidade e uso do aplicativo a partir de um terceiro olhar. 
Inicialmente, o trabalho se deu despretensiosamente no desenvolvimento de um jogo relacionado ao conteúdo que estava sendo abordado em onze (11) turmas distintas do ensino médio/ técnico na ETESC/FAETEC, como forma avaliativa para os alunos.

A partir deste trabalho, algumas turmas apresentaram destaque, no desenvolvimento da elaboração de "jogos" relacionados ao conteúdo de química, dentre estas turmas, destacou-se a turma de primeiro ano do ensino médio/técnico em informática no ano de 2017.

Cada grupo da turma ficou responsável e livre para tratar de um ou mais assuntos abordados durante o trimestre, no desenvolvimento de um determinado "jogo”. Assim, cada grupo desenvolveu um jogo diferente, tendo como resultado três grupos, que apresentaram propostas diferenciadas de “jogos”.

Nesta turma, um determinado grupo de alunos, desenvolveu um aplicativo que se baseava em um quiz de perguntas e respostas sobre os temas: Tabela periódica, Ligações químicas e funções inorgânicas, no qual foi um grande destaque em relação à criatividade e a interdisciplinaridade entre a química e a informática. Os outros grupos também desenvolveram jogos a partir do mesmo tema proposto (Tabela periódica, Ligações químicas e funções inorgânicas), porém o desenvolvimento do aplicativo despertou maior interesse e curiosidade entre os 
próprios estudantes, na utilização deste jogo desenvolvido por este determinado grupo de alunos da turma de ensino médio/técnico em informática.

Estas apresentações realizadas para o professor, dos grupos que desenvolveram os jogos abordando conceitos químicos, como forma de avaliação para os alunos, foram realizadas em sala de aula, com uma duração de dois tempos de 50 minutos cada.

Com o desenvolvimento do primeiro aplicativo realizado pelos alunos sobre Tabela periódica, Ligações químicas e funções inorgânicas, foi então proposto à turma o desenvolvimento de um novo aplicativo, no qual contextualizasse o tema combustível. Com isto, seria necessário trabalhar conceitos químicos, para que os alunos obtivessem melhor compreendimento sobre o tema.

Fase II - Proposição do tema gerador biocombustíveis

A contextualização temática sobre combustíveis, biocombustíveis e biodiesel (etapa 1) foi desenvolvida em duas aulas, com dois tempos para cada aula, em um total de 50 minutos para cada aula. A proposição (etapa 2) e divisão dos alunos em grupos, com atividades diferenciadas (etapa 3) foram realizadas após o término das aulas teóricas em sala de aula. 
Fase III - Desenvolvimento do aplicativo feito pelos alunos com o tema gerador

O desenvolvimento do aplicativo (etapa 4) e a seleção dos itens relativos ao tema gerador a serem utilizados no aplicativo (etapa 5), que foram elaborados na escola, foram realizados em duas aulas, com dois tempos para cada aula de 50 minutos. A seleção dos itens relativos ao tema gerador a serem utilizados no aplicativo (etapa 5) também ocorreu via e-mail eletrônico, como também com o uso do aplicativo WhatsApp, seguida da etapa de elaboração das perguntas, feita pelos alunos e mediada pela docente, ao longo do trimestre.

Fase IV-A contextualização temática do tema combustível e a utilização do espaço não-formal da Nave do Conhecimento

Durante o desenvolvimento do aplicativo, foram observadas grandes dificuldades na compreensão dos conceitos químicos, agravadas por um contexto social no qual os alunos são vítimas de problemas de violência no bairro, como assaltos, tráfico de drogas e guerra entre facções criminosas. Esses fatores influenciam na baixa frequência dos alunos na escola em geral e desmotivação, chegando ao descrédito na aprendizagem e nas suas próprias realizações. 
A proposição de se utilizar o espaço da Nave do Conhecimento surgiu dos próprios alunos que numa roda de conversa sobre a temática abordada na aula de Química, manifestaram o desejo de frequentar o espaço que é gratuito e representa a única possibilidade para muitos deles para acessar a internet.

O projeto, então, começou a ser desenvolvido a partir de uma iniciativa dos próprios alunos, em um processo de valorização das suas autonomias e habilidades. Estabeleceu-se, assim, a construção da relação da química com a informática, mediado pelo uso de um espaço não-formal, fora dos "muros da escola" (MARANDINO, 2017), o que fortaleceram ainda mais o protagonismo dos alunos.

A partir disto, consequentemente, os alunos mostraram-se mais próximos e mais motivados na confecção deste trabalho, pois foi utilizado um espaço em comum e habitual dos alunos, inserido no cotidiano de espaço deles, no qual a mediadora sai do espaço formal de sala de aula e passa a frequentar um espaço não formal, de uso contínuo dos alunos. Isso fez com que os alunos se sentissem mais a vontade para elaborar o trabalho e mais confiantes também.

E foi assim, a partir de uma proposição dos próprios alunos que o aplicativo foi desenvolvido inteiramente por eles no espaço não-formal da Nave do Conheci- 
mento, onde puderem ter acesso aos computadores e à rede local. Os alunos desenvolveram o aplicativo empregando o software Unity, assim como, do adobe photoshop e adobe illustrator para o design e elaboração das perguntas contextualizadas em combustíveis.

Fase V - Apresentação, utilização e avaliação do aplicativo móvel "FUEL ASK".

A avaliação dos primeiros testes do aplicativo FUEL ASK (figura 1, 2 e 3), feito entre os alunos, foi realizada pelos alunos num espaço de tempo de uma semana, e a apresentação do uso do aplicativo para a turma e para a docente foi realizada em uma aula de dois tempos, com 50 minutos para cada aula.

Este trabalho teve duração do início do segundo trimestre até o final do terceiro trimestre no ano de 2017. Em 2018, demos continuidade a este trabalho, aprimorando-o de forma a contextualizar conceitos químicos mais profundamente, como no estudo da química orgânica, por exemplo, e então podermos corrigir e melhorar o aplicativo desenvolvido sobre combustíveis.

$\mathrm{Na}$ etapa final, os alunos apresentaram este trabalho para outra turma de ensino médio/técnico de informática, mediada pela docente, em que os alunos apresentaram o funcionamento do aplicativo "FUEL ASK" 
(Figuras 1 e 2) e sua aplicabilidade no dia a dia, que teve uma duração de 4 tempos de aula, totalizando $200 \mathrm{minu}$ tos.

Os alunos da outra turma avaliaram o aplicativo desenvolvido, a sua funcionalidade e aplicação, assim como a viabilidade e seu uso em sala de aula ou para outros tipos de uso no dia a dia, como forma interativa.

A avaliação do projeto baseou-se em duas frentes:

a) a realização de entrevistas com os alunos participantes, realizados sob a forma de áudios com o uso do what$s A p p$, estimulando-os a dar suas opiniões de forma livre e

b) o emprego de questionários híbridos, semiestruturados, propostos nos anos letivos de 2017 e 2018 e disponibilizados na dissertação de mestrado relacionada ao trabalho. 
Figura 1: Aplicativo "Fuel Ask": Imagens ilustrativas da configuração inicial do aplicativo desenvolvido pelos alunos

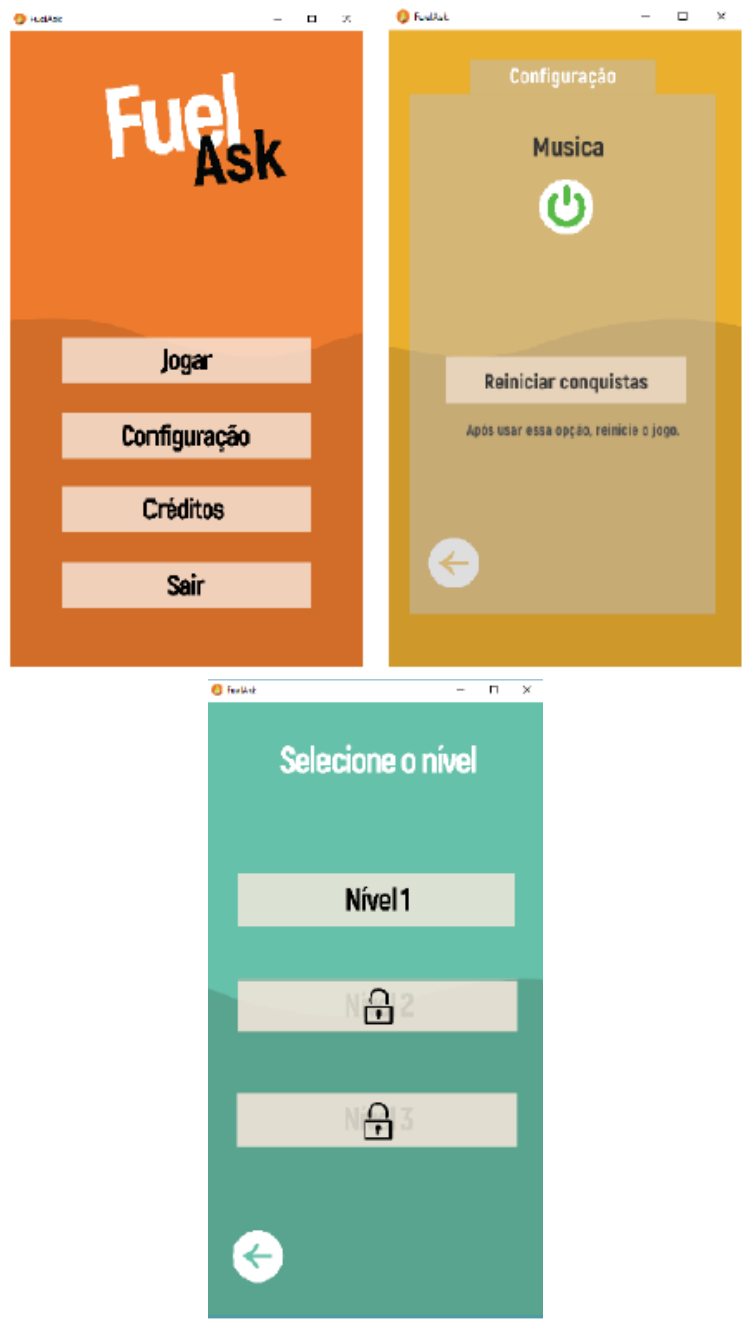

Fonte: Autoras 
Figura 2. Perguntas elaboradas pelos próprios alunos para o Nível 1 do aplicativo

Perguntas sobre o nível 1 do jogo "FUEL ASK":

\begin{tabular}{|l|}
\hline \multicolumn{1}{|c|}{ NÍVEL 1} \\
\hline 1 - É possível fazer energia queimando combustível? Verdadeira \\
\hline 2 - Gasolina é um tipo de combustível fóssil? Verdadeira \\
\hline - Diesel é um tipo de biocombustível. Falsa \\
\hline 4 - Etanol é um tipo de biocombustível. Verdadeira \\
\hline 5 - O diesel apresenta em sua composição $8 \%$ de gasolina. Falsa \\
\hline 6 - O etanol hidratado apresenta origem do petróleo. Falsa \\
\hline $\begin{array}{l}\text { 7 - A substância principal do GNV é o etanol, conhecido também como álcool } \\
\text { etílico. Falsa }\end{array}$ \\
\hline
\end{tabular}

Fonte: Autoras

\section{Resultados e discussão}

Este trabalho foi desenvolvido em uma turma de ensino médio/ técnico em informática, apresentando um total de aproximadamente 20 alunos, destacando que metade da turma apresentou-se na linha de frente na elaboração do trabalho, porém todos foram presentes de alguma forma para a elaboração e desenvolvimento do trabalho.

O aplicativo realizado foi obtido de forma satisfatória e de compreensão dos alunos, além de contextualizar as técnicas de informática e o ensino de química. De acordo com o depoimento dos alunos, podemos observar 
que o aplicativo desenvolvido foi utilizado por eles de forma lúdica contribuindo para a aprendizagem do tema combustíveis.

A avaliação sobre o discurso dos alunos a ser apresentada neste trabalho foi relatada com base nas respostas obtidas a partir da pergunta realizada a eles: "O que este trabalho sobre combustíveis pode acrescentar para vocês no conhecimento químico e na área de informática, em que vocês atuam?”. Analisando-se os discursos dos alunos sob a ótica do construtivismo crítico de Paulo Freire (1996), foi possível observar excertos que ressaltaram o aluno como sendo protagonista do seu próprio processo de aprendizagem, como podemos ver nos trechos das falas dos alunos destacados abaixo:

A1: “... aprendi mais uma linguagem de programação e também aprendi a usar uma nova ferramenta de criação... consegui aprender mais sobre combustíveis, tanto no aplicativo como nas palestras que a professora deu, para nos ajudar a montar esse aplicativo".

A2: “... eu aprendi mais sobre o conteúdo abordado no jogo. Foi bastante interessante”.

A3: “... me deu alguns conhecimentos na área da programação e do designer e me acrescentou várias coisas, além do que, claro, que houve uma pesquisa por trás das perguntas do jogo, e isso acabou me dando alguns conhecimen- 
tos sobre combustíveis, ajudou em química e em vários outros quesitos...”.

A4: "... Achei algo em que eu nunca realmente tinha me aprimorado em todo esse tempo: designer;... Nunca consegui fazer algo em que eu mergulhasse durante todas as minhas tentativas".

O processo de mediação (VIGOSTKI, 1991) pôde ser observado nos seguintes discursos dos alunos:

A5: “... com as palestras da professora Cinthia, eu obtive mais conhecimento sobre o assunto abordado, que foi combustíveis, e isso vai me ajudar bastante para o futuro".

A6: “... A professora nos ajudou também bastante com este jogo, ensinando a gente de como são feitos, de que são feitos e para que servem os combustíveis".

A presença da contextualização e da interdisciplinaridade entre os domínios dos conteúdos da Química e da Informática pode ser observado nos seguintes fragmentos de discursos:

A7: "Este trabalho sobre biocombustíveis me acrescentou um conhecimento técnico sobre o assunto que irá me ajudar principalmente na área química,..., me permitindo um olhar mais brando sobre os combustíveis em geral, que é algo que está amplamente presente em nosso cotidiano. Na minha área técnica, que é informática, este trabalho ajudou muito 
na aprendizagem do desenvolvimento de software, uma área abrangente e que, com uma pequena base, muito já pode ser feito, e tais softwares que forem desenvolvidos podem ser reconhecidos por muitos, e ser de grande ajuda para empresas, corporações e pessoas".

Com relação à análise da aprendizagem em equipe e a cooperação, importantes aspectos para a formação humana e grande desafio para a carreira profissional, alguns trechos foram destacados:

A8: "... o trabalho ajuda a crescer de alguma forma a capacidade intelectual...”.

A9: “... em lidar em situação de grupo me ajudou bastante. Então, este projeto acrescentou bastante coisa para mim e pode me servir em algumas coisas no futuro".

A10: "Eu consegui derrotar um medo irracional que eu tinha e saber utilizar uma nova ferramenta para trabalhar no futuro".

A11: “... ele me ajudou a desenvolver um método de pesquisa, a trabalhar em equipe, o que é necessário para uma carreira profissional".

A12: "Para mim este projeto foi importante para o meu futuro, não só o meu, mas também para os outros desenvolvedores... E o jogo também nos proporcionou a ideia de como será o trabalho futuro de um programador, inclusive no trabalho em equipe". 
Analisando-se os discursos através de uma análise de Educação Ambiental, destacamos:

A13: "Este trabalho sobre biocombustíveis me acrescentou um conhecimento técnico sobre o assunto que irá me ajudar principalmente na área química, me ajudando a reconhecer com o que estou trabalhando e desenvolvendo, quando mexer com este tipo de substância, me permitindo um olhar mais brando sobre os combustíveis em geral, que é algo que está amplamente presente em nosso cotidiano...”.

A14: "... além do que, claro, que houve uma pesquisa por trás das perguntas do jogo, e isso acabou me dando alguns conhecimentos sobre combustíveis, ajudou em química e em vários outros quesitos...”.•

\section{Considerações finais}

A ideia do trabalho foi promover o "diálogo" entre dois campos de domínio, a Química e a Informática, contextualizados com o tema combustíveis e biodiesel, através do desenvolvimento de atividades cooperativas realizadas pelos próprios alunos do ensino médio. Sendo os protagonistas de suas aprendizagens, os alunos mostraram-se participativos e empenhados durante todo o trabalho realizado, estando presentes em diversos encontros durante o final do período de 2017. Os alunos também puderam se apropriar dos conhecimentos científicos 
necessários para importantes mudanças em relação aos argumentos relacionados à problematização do uso dos combustíveis.

Nessa perspectiva, aspectos econômicos, sociais, ambientais e questões sobre o consumismo excessivo de combustíveis passaram a fazer parte da compreensão dos alunos. Portanto, o produto das atividades dos alunos, neste trabalho, não se restringiu ao desenvolvimento do aplicativo feito por eles mesmos, mas abrangeu a contextualização de conceitos científicos discutidos e aprofundados nos momentos anteriores, tornando-os capazes de articular tais conhecimentos em diferentes situações da vida cotidiana.

O envolvimento dos alunos durante a sequência de ensino e o posicionamento crítico que adquiriram ao final das discussões acerca dos fatores que consideravam mais relevantes para encadear o tema ao jogo foi um forte indicativo das possibilidades de aplicação dos conhecimentos na perspectiva discutida neste trabalho. Assim, o uso de TDIC, de modo inter-relacionado, contextualizado, participativo e interdisciplinar pode ser uma metodologia muito interessante para o processo de aprendizagem a ser empregada tanto no ensino de Química, como de outras disciplinas do ensino médio.

O aplicativo realizado foi obtido de forma satisfatória e de compreensão dos alunos, além de contextuali- 
zar as técnicas de informática e o ensino de química. De acordo com o depoimento dos alunos, podemos observar que o aplicativo desenvolvido foi utilizado por eles de forma lúdica contribuindo para a aprendizagem do tema combustível.

Além disto, houve a valorização do conhecimento da informática, e que através das aulas em sala de aula, pode-se estabelecer essa conexão com o ensino de química, destacando assim, a motivação para o conhecimento e a interdisciplinarização destas disciplinas. Sendo assim, foi através dessa temática, em que podemos observar que houve a construção de uma relação mais afetiva inter e intra grupos, e consequentemente com o professor mediador.

Portanto, pode-se observar que os alunos se mostraram mais participativos em sala de aula e muito mais motivados, já que o conhecimento de informática foi concretizado no aprendizado do conteúdo de química, ou seja, foi construído pelas próprias mãos de quem aprende.

\section{Referências}

ALMEIDA, C. D. "FUEL ASK": O Desenvolvimento de um Aplicativo na Contextualização do Tema Combustíveis no Ensino de Química. Tese (Mestrado em Ensino de Química - 
Modalidade Profissional) - Instituto de Química, Universidade Federal do Rio de Janeiro. Rio de Janeiro, p.135. 2019

CINELLI, N. A influência do vídeo no processo de aprendizagem. Programa de Pós-graduação em Engenharia de Produção, Florianópolis, 2003. Disponível em: <http://coral.ufsm.br/tielletcab/Nusi/HiperV/Biblio/PDF/81 6o.pdf > . Acesso em: 12 dez. 2017.

FREIRE, P. Pedagogia da autonomia: saberes necessários à prática educativa. São Paulo: Paz e Terra, 1996.

. Educação e mudança. $30^{\mathrm{a}}$ ed.; Rio de Janeiro: Paz e Terra, 1979.

. Conscientização: Teoria e prática da libertação: Uma introdução ao pensamento de Paulo Freire. $3^{\mathrm{a}}$ ed.; São Paulo: Centauro, 2006.

Terra, 2006.

. Pedagogia da esperança. 13a ed. Rio de Janeiro: Paz e

HADDAD, W., JURICH S. (2017). ICT for education: Potential and potency in technologies for education. Effects of Information and Communication Technology (ICT) prospects, 4 (1), pp 28-40.

LOUREIRO, C. F. B. Educação Ambiental Transformadora. In: Layrargues, P. P. (Coord.) Identidades da Educação Ambiental Brasileira. Brasília: Ministério do Meio Ambiente, 2004.

MAHI, M.H, TARANNOOM, T., ISLAM, M.A., KHAN, M.M (2019). A Web Based Interactive System to Promote ICT Education in Bangladesh. In 14th International Conference on Computer Science \& Education (ICCSE), Toronto, Canada, pp. 77-80, 2019. 
MARANDINO, M. A educação não formal e a divulgação científica: o que pensa quem faz? IV encontro nacional de pesquisa em educação em ciências. Disponível em: < http://abrapecnet.org.br/enpec/iv-enpec/orais/ORALoo9.pdf > Acesso em: 14 dez. 2017.

MATEUS, A. L. Ensino de química mediado pelas TICs. Editora UFMG. 197 p., p.97-98, 2015.

RIO DE JANEIRO. Prefeitura do Rio de Janeiro (Org.). Nave do Conhecimento. Disponível em: <https://navedoconhecimento.rio/>. Acesso em: 27 jun. 2018.

SILVA, R.M.G. Contextualizando aprendizagens em química na formação escolar. Química Nova na Escola, n.18, p. 26 30, 2003.

VYGOTSKI, L. S. A formação social da mente. São Paulo: Martins Fontes, $4^{\mathrm{a}}$ Edição, 1991.

. A formação social da mente: o desenvolvimento dos processos psicológicos superiores. São Paulo: Martins Fontes, 1998. 